\title{
MIDAS
}

Museus e estudos interdisciplinares

$5 \mid 2015$

Varia e dossier temático: "Ciência e arte, SciArt: museus, laboratórios, cientistas e artistas"

\section{Linda Norris e Rainey Tisdale - Creativity in Museum Practice}

Inês Ferreira

\section{OpenEdition}

\section{Journals}

Edição electrónica

URL: http://journals.openedition.org/midas/917

DOI: $10.4000 /$ midas. 917

ISSN: 2182-9543

\section{Editora:}

Alice Semedo, Paulo Simões Rodrigues, Pedro Casaleiro, Raquel Henriques da Silva, Ana Carvalho

\section{Refêrencia eletrónica}

Inês Ferreira, "Linda Norris e Rainey Tisdale - Creativity in Museum Practice », MIDAS [Online], 5 | 2015, posto online no dia 03 dezembro 2015, consultado no dia 24 setembro 2020. URL : http:// journals.openedition.org/midas/917; DOI : https://doi.org/10.4000/midas.917

\section{Este documento foi criado de forma automática no dia 24 setembro 2020.}

\section{cc) (1) (ㅇ)}

Midas is licensed under a Creative Commons Attribution-NonCommercial-ShareAlike 3.0 International License 


\title{
Linda Norris e Rainey Tisdale - Creativity in Museum Practice
}

\author{
Inês Ferreira
}

\section{REFERÊNCIA}

Norris, Linda, e Rainey Tisdale. 2014. Creativity in Museum Practice. Walnut Creek, California: Left Coast Press Inc. 246 páginas, ISBN: 13:978-1-61132-308-5.

1 O título - Creativity in Museum Practice - aponta para o caráter prático e operacional desta publicação. Ao longo de cinco capítulos, Linda Norris e Rainey Tisdale cruzam uma contextualização teórica sobre a criatividade nos museus, as áreas em que esta pode ser trabalhada e os instrumentos para o fazer, com um vasto conjunto de práticas e experiências levadas a cabo em museus de diversas partes do mundo. Como referem as autoras, «this book is one part manifesto to three parts toolkit» (p. 15), traduzindo bem o objetivo do livro: desafiar cada leitor a partir do pensar para o experimentar.

2 O processo de escrita do livro foi, em si, um processo criativo. Linda Norris e Rainey Tisdale são duas profissionais de museus independentes que, quando começaram este projeto editorial, só se conheciam através da escrita dos blogues de cada uma, The Uncatalogued (de Linda Norris) e City Stories (de Rainey Tisdale). Juntas construíram a ideia do projeto, que se foi alimentando de um conjunto de fontes muito variadas: uma literatura vasta e diversificada, a observação em museus do mundo inteiro e nos seus bastidores, a participação em encontros e conferências, a manutenção de conversas e entrevistas com profissionais, a participação em blogues e os encontros semanais, via Skype, entre as autoras. 0 processo de fim aberto, flexível e iterativo da construção do projeto é algo que se destaca, pela capacidade de gerar e relacionar ideias vindas de contextos tão distintos.

3 A criatividade de todos os dias, a que se refere o livro - que todos têm - implica treino. Mencionam as autoras que «like any other muscle you want to develop, you just have to exercise your creative thinking regularly and vigorously in order to strengthen it» (p. 
28). Para ajudar o leitor a partir do pensamento para a ação as autoras polvilham cada capítulo com uma série de exemplos estruturados em duas categorias: Your Creative Practice, relatos de histórias de profissionais acerca do que funcionou com eles e nos museus onde trabalham; Try This, ideias concretas, sem custos ou de baixo custo, que qualquer um pode experimentar para melhorar as suas práticas criativas. Os exemplos e testemunhos na primeira pessoa surgiram exatamente da partilha no blogue que as autoras mantiveram durante o processo de construção do livro (http:// creativityinmuseumpractice.worldpress.com/), onde recolheram testemunhos de profissionais de todo o mundo que partilharam as suas histórias e práticas. Esse blogue continua a ser alimentado pelas autoras, reforçando o caráter colaborativo do projeto e a ideia de que a criatividade está sempre em desenvolvimento. Se o vasto conjunto de exemplos é uma fonte rica de inspiração, questiona-se se o leitor poderá perder-se no meio de tantos testemunhos e se um menor número de exemplificações, mais aprofundadas, poderia eventualmente ser mais útil.

o livro pretende explorar como é que se pode difundir o potencial criativo dos profissionais e dos serviços dos museus, através da instituição e da sociedade. Partindo da investigação, da autorreflexão e partilha, as autoras apresentam dicas para desenvolver a criatividade no dia a dia em tarefas tão distintas como a gestão, o desenvolvimento de métodos interpretativos, as estratégias de fundraising ou a geração de ideias e a resolução de problemas em qualquer departamento de um museu. Ao moverem-se através da criatividade do profissional, da organização, do público e da sociedade, as autoras revelam a complexidade do museu, enquanto sistema criativo, em que todas as partes se interrelacionam.

5 Porquê um livro como este? As autoras partem da convicção de que qualquer profissional do museu - curador, educador, frente-de-casa, segurança, gestor - tem energia criativa que, quanto mais a desenvolver, ele próprio, o museu e a sociedade ganham com isso, porque um museu criativo ajuda qualquer um a descobrir a sua própria criatividade e a usá-la para resolver problemas.

6 O livro começa por justificar, na introdução (p. 10-14) porque é que a criatividade é relevante hoje nos museus, sendo esta justificação o pilar e a razão de ser de tudo o que se segue. Cada capítulo abre com uma citação que funciona como gancho para o que vem a seguir.

70 primeiro capítulo foca-se no desenvolvimento das práticas criativas individuais, reforçando a ideia de que a criatividade é importante para todos e se pode treinar. Percorrendo uma série de estratégias que alimentam a criatividade - desenvolver hábitos criativos e reflexivos, pensar fora da caixa, buscar inspiração fora da área de cada um, aumentar o contacto com a diversidade - as autoras vão cruzando o pensamento de alguns investigadores com ideias muito concretas que cada pessoa pode praticar.

8 O segundo capítulo centra-se no desenvolvimento da criatividade no museu, enquanto sistema organizativo complexo. A questão que orienta este capítulo é de como é que a liderança no museu pode encorajar a criatividade e a capacidade de risco da organização. Premiar a capacidade de arriscar e as ideias criativas, reportar o trabalho criativo periodicamente à direção, integrar atividades criativas nas reuniões de trabalho, providenciar um equilíbrio entre liberdade e constrangimentos, ser mais tolerante com as falhas, são algumas das estratégias discutidas neste capítulo, para promover a criatividade na cultura de uma organização museológica. 
O terceiro capítulo apresenta diversos instrumentos para tornar os espaços e o próprio trabalho no museu mais criativo e o quarto capítulo olha toda a infraestrutura do campo dos museus, que se alarga através de uma imensa rede virtual de conexões, para aí descobrir novas possibilidades criativas. Ou seja, o uso das ferramentas, apontadas no terceiro capítulo, tem sentido tendo em vista o horizonte das redes e das relações apontado no quarto capítulo, que inicia com uma frase inspiradora de Antoine SaintExupéry: «If you want to build a ship, don't drum up people to collect wood and don't assign them tasks and work, but rather teach them to long for the endless immensity of the sea» (p. 139).

o quinto e último capítulo foca, em paralelo, museus e comunidades criativas, numa perspetiva de demonstrar como é que os museus podem fortalecer a criatividade das comunidades. Neste capítulo é apresentada uma imagem metafórica do museu especialmente feliz - o museu como um espaço que providencia oportunidades para a polinização cruzada:

Cross-pollination in the service of creativity is about getting outside your comfort zone - your narrow knowledge base and frame of reference - and opening yourself up to a host of possibilities through new information, new approaches, new juxtapositions, and new experiences. Museums are uniquely positioned to aid the associative thinking and idea combination that comes from cross-pollination by exposing people to a broad range of knowledge, artefacts, and points of view from multiple disciplines and cultures, and mixing them in new ways (p. 183).

11 As autoras referem-se à polinização cruzada nos museus a dois níveis. Por um lado, trazer pessoas de diferentes áreas e disciplinas para falar de objetos como uma forma de potenciar a polinização cruzada; por outro lado, as próprias coleções ao constituírem uma oportunidade de polinização cruzada, se as olharmos de diferentes pontos de vista.

12 No final, a publicação integra um guia para promover a criatividade na prática dos museus, com dicas estruturadas pelos diferentes capítulos, assim como um jogo para o leitor selecionar uma atividade criativa a desenvolver. Apresenta ainda uma vasta bibliografia, que se estende pelos campos da museologia, da psicologia, da sociologia, dos estudos culturais, entre outros, reforçando a natureza transversal e interdisciplinar da criatividade.

13 O caráter prático e operacional do livro pode fazer dele uma excelente ferramenta de trabalho e desenvolvimento pessoal. Esse caráter "instrumental" pode, no entanto, constituir simultaneamente uma fragilidade, se o livro for encarado como um conjunto de ideias e receitas, a aplicar. As próprias autoras referem que a criatividade implica método e prática, o que justifica um livro com este formato, mas também referem que não há receitas para a criatividade. Cada um, recorrendo às mesmas ferramentas, tem de encontrar as suas próprias ideias e soluções, e traçar o seu próprio caminho.

Se, hoje, a literatura disponível em criatividade é vasta, as publicações que abordam a criatividade especificamente no contexto dos museus são poucas. Podem encontrar-se artigos dispersos por publicações periódicas (por exemplo, no Curator, The Museum Journal) e por blogues (por exemplo, The Future of Museums) e destaca-se ainda um número do JME - Journal of Museum Education (30, n. 1, janeiro 2005) - integralmente dedicado à criatividade nos museus. $O$ que este livro - Creativity in Museum Practice traz de novidade é uma abordagem do tema de forma mais complexa, articulada e contextualizada. 

uma enorme quantidade de fontes - bibliográficas, visitas, entrevistas, conversas, partilha de experiências - que se considera um formato com potencial. Destaca-se ainda o facto do texto proporcionar uma leitura estruturada, de uma ponta à outra, ou também uma leitura solta e mais desestruturada, de um capítulo, umas páginas, um exemplo ou testemunho. É um livro que exige tempo de reflexão e de maturação, pode ler-se e reler-se, ou pode ir-se lendo, uma parte, outra parte, cruzando com a vida pessoal e a profissional, mas é necessário personalizar-se o que se lê, fazer-se seu.

Por tudo isto, trata-se de uma publicação útil para os profissionais de qualquer área dos museus que queiram aproximar-se da criatividade no seu trabalho quotidiano. Constitui também uma leitura recomendável para estudantes e investigadores que pretendam refletir sobre o papel criativo dos museus e o papel da criatividade nos museus.

\section{AUTORES}

\section{INÊS FERREIRA}

Câmara Municipal do Porto, bolseira da Fundação para a Ciência e a Tecnologia, Portugal, inesspratleyferreira@gmail.com 